\title{
Ein Fall von Rückkehr qualitativer Lichtempfindung nach Iridektomie bei Amaurosis in Folge ron Glancoma simplex.
}

\author{
Von \\ Dr. L. Kugel, \\ Primärarzt der Augenabtheilung am Alexanderhospital in Sofia.
}

Am 26. August vergangenen Jahres kam der 30jährige, rüstige Baner Karamfil Mladenof auf meine Augenabtheilung mit typischem Glaucoma simplex beider Augen; es war keine Spur von Lichtempfindung vorhanden. Die $A b$ nahme der Sehschärfe, welche mit allmählicher Einengung des Gesichtsfeldes einherging, soll vor 6 Wochen begonnen haben (auf dem linken Auge 2 Tage friher) und in den nächsten 14 Tagen so rapid fortgeschritten sein, dass zuerst das rechte und drei Tage später das linke Auge vollkommen amaurotisch wurde.

Am 27. August iridektomirte ich beiderseits in der Absicht, eventuellen später eintretenden Schmerzen vorzubeugen, und dem Kranken den weiten Weg nach Sofia zu ersparen. Ueberraschte es mich schon, dass am 30. August prompte Lichtempfindung beiderseits zurïckgekehrt war, so war ich drei Tage später noch mehr erstaunt, auf beiden Augen den Eintritt qualitativer Lichtempfindung constatiren zu können. Mit dem rechten Auge wurden in der Nähe die Bewegungen der Hand deutlich wahrgenom- 
men; mit dem linken konnten sogar Finger bis auf $40 \mathrm{~cm}$ prompt gezählt werden. In den nächsten 8 Tagen war kaum noch eine geringe Besserung bemerkbar. Durch den Erfolg anfgemuntert, vollzog ich am 12. September wieder die Iridektomie beiderseits. Jetzt kam die Besserung wieder in Gang, so dass der Patient am 26. September mit dem rechten Auge Finger in $10 \mathrm{~cm}$, mit dem linken auf $1 \mathrm{~m}$ zählen konnte. Am 5. November, als der Kranke das Spital verliess, war der Zustand des linken Auges noch etwas gebessert (Finger werden jetzt auf $1 \mathrm{~m} 20 \mathrm{~cm}$ gezähIt); rechts war eine geringe Abnahme der Sehschärfe zu constatiren, indem die Finger auf $10 \mathrm{~cm}$ Distanz nicht mehr so sicher als früher gezählt wurden. Die Gesichtsfelder zeigten beiderseits starke Einengung und zwar das rechte mehr als das linke; beiderseits war die Einengung in verticaler Richtung mehr prononcirt als in horizontaler. Auffallend war der Unterschied im Augenspiegelbefunde, wie er beim Eintritt und wie er beim Austritt des Kranken aus dem Spitale sich zeigte. Vor der Iridektomie war beiderseits starke Sehnervenexcavation, Gefässverschiebung gegen den äusseren Sehnervenrand und starke bläuliche Verfärbung des Sehnerven vorhanden. Beim Verlassen des Spitales war am linken Auge die Gefässverschiebung ganz verschwunden, rechts bedeutend verringert; die bläuliche Verfärbung des Sehnerven hatte rechts einer weisslichen den Platz gerïumt, während mir links der Sehnerv, was Farbe anlangt, normal erschien. Die früher bestandene bedeutende Excavation war links jetzt fast ganz geschwunden; rechts hatte dieselbe bedeutend abgenommen. Pulsation der Netzhautgefässe war ebenfalls geschwunden. Die früher beiderseitig erhöhte Tension der bulbi zeigte sich jetzt normal.

Dass verloren gegangene quantitative und sogar qualitative Lichtempfindung bei Glaukom in Folge von Iridektomie zurickkehren kann, ist bis jetzt bloss bei den acutesten 
Ein Fall von Rückkehr qualitativer Lichtempfindung ete. 301 entzündlichen Fällen, den sogenannten fulminanten Krankheiten, beobachtet worden, und selbst für diese Fälle scheint es mir zweifelhaft, ob nicht, wenigstens in einer gewissen Quote, die etwa noch vorhandene geringe Perceptionsfähigkeit der Netzhaut, durch die starken Trübungen der durchsichtigen Medien gedeckt wird, so dass wir es mehr mit einer scheinbaren als factischen Amaurose zu thun hätten. Bei dem eben mitgetheilten Fall sehen wir jedoch merkwürdiger Weise Wiederkehr quantitativer und qualitativer Lichtempfindung bei Glaucoma simplex, einer Glaukomform, wo wir gewohnt sind, unsere Hoffmungen auf den Erfolg der Iridektomie auf ein bescheidenes Maass zu reduciren. Eine weitere Beachtung verdient auch das lange Bestehen der präexistirenden Amaurose. Prof. v. Graefe ${ }^{1}$ ) hatte bei einem Falle von Glaucoma fulminans nach 14 tägigem Bestande der Amaurose durch Iridektomic keinen Erfolg. Auffallend war mir ferner das fast gänzliche Verschwinden der tiefen Excavation linkerseits, respective die Herstellung des früher am Sehnervenrande unterbrochen erscheinenden Verlaufes der Netzhautgefässe in Folge der Operation, sowie auch die Rückschiebung der Gefässe vom Rande gegen die Mitte der Sehnervenscheibe. Tch habe eine so hochgradige Besserung im Zustande des Sehnerven bis jetzt nicht gesehen. Hervorzuheben wäre endlich noch der relativ schnelle Verfall der Sehkraft (während 14 Tage bis zur vollkommenen Amaurose) bei Glaucoma simplex.

1) v. Graefe's Archiv für Ophthalmologie VIII. 2, S. 253. 